\title{
Increasing the productivity of a plant for moisture evaporation from oil sludge by application of efficient method for technological parameters calculation
}

\author{
Alisa Surikova ${ }^{1, *}$, Elena Sytsyanko ${ }^{1}$, Ekaterina Solov'eva ${ }^{1}$ and Liliya Mukhametova ${ }^{2}$ \\ ${ }^{1}$ Vologda State University, Lenina str. 15, 160000, Russia \\ ${ }^{2}$ Kazan State Power Engineering University, Kazan, Russia
}

\begin{abstract}
The paper presents the method of heat calculation of recovery stages for the plant of moisture evaporation from oil sludge. It enables to increase the plant power and reduce fuel consumption per one unit of evaporated moisture in heating boiler.
\end{abstract}

\section{Introduction}

At the modern stage of chemistry and petrochemistry development, the processes of management of waste, including oil and sludge, are under strict complex requirements. These include reducing energy and resource consumption, increasing their technical and economic efficiency, ensuring environmental safety according to the world standards [1,2]. The existing technologies for oil sludge disposal often do not respond to the stated requirements, and have a negative impact on the environment by their own waste, which have to be buried.

Over the past decades, various technological solutions for disposal of oil sludge have been proposed. However, despite the achieved results, these technologies need significant improvement due to annual enforcement of laws related to environmental protection and increasing requirements for their performance.

The issues of processing and using the resource potential of chemical, petrochemical, oil production waste and heavy oil residues (oil sludge) and assessing their environmental impact were considered in works of many Soviet and Russian scientists, such as: R.Kh. Fassakhov, M.Yu. Malikova, N.S. Yamanina, A.A. Desyatkin, T.A. Kulagina, A.F. Nadein, L.K. Altunina, L.I. Swarovskaya, A.Yu. Evdokimov, N.T. Elovshin, I.V. Efremov, A.G. Ishkov, V.M. Ferdman, A.B. Dmitrevsky, N.L. Guryleva, V.G. Maksimovich, V.A. Argunov, O.G. Fetisov, B.E. Prusenko, G.L. Handel, N.V. Lavrov, R.V. Surzhikova, M.S. Shpinkova, T.Sh. Aksanov, G.G. Gladyshev, N.M. Ismailov and others.

But despite the obvious urgency of the problem of oil sludge disposal, such productions are still not as widespread as required. This is explained by the fact that such plants, both Russian and international, have a high cost with low productivity and efficiency. In recent times oil sludge separation units (BRNSh) are the most promising in the field of oil-containing waste recovery
[3]. Such plants are based on evaporation of moisture from oil sludge waste, they also can be potentially improved and achieve higher energy efficiency.

In the present work, a method of thermal calculation of a plant for moisture evaporation from petroleum products is proposed. Using it, technological parameters are identified that significantly affect the performance and thermal efficiency of the BRNSh-3 unit (the number " 3 " means the volume of oil sludge (m3) loaded in plant) [4].

\section{Technological scheme of BRNSh plant}

To determine the potential for improving and increasing efficiency of the oil sludge separation unit (BRNSh) an efficient design scheme is proposed [3]. Using variable approaches the proposed calculation procedure allows one to introduce new technological modes and thereby increase the thermal efficiency and productivity of the considered plant.

Consider the technological scheme and operation principle of BRNSh.

Figure 1 shows the technological thermal scheme of plant for moisture evaporation from oil sludge with additional recovery heat exchangers.

The technological scheme of plant consists of the following stages: WHB is water heating boiler; ES is evaporation stage (main), heated by water from boiler; $\mathrm{RS}$ is recovery evaporation stage; OR is recovery heater of oil sludge; WP is vacuum water ring pump; $S$ is separator; $\mathrm{K}$ is calorifer. The plant includes the following elements: circulation pump for water and oil sludge; lines of heating and cooling water, steam and condensate [5].

The plant has the following operation stages:

1. The preheated oil sludge in equal volumes is loaded into the main and recovery evaporation stages.

Corresponding author: alisa-surikova@bk.ru 


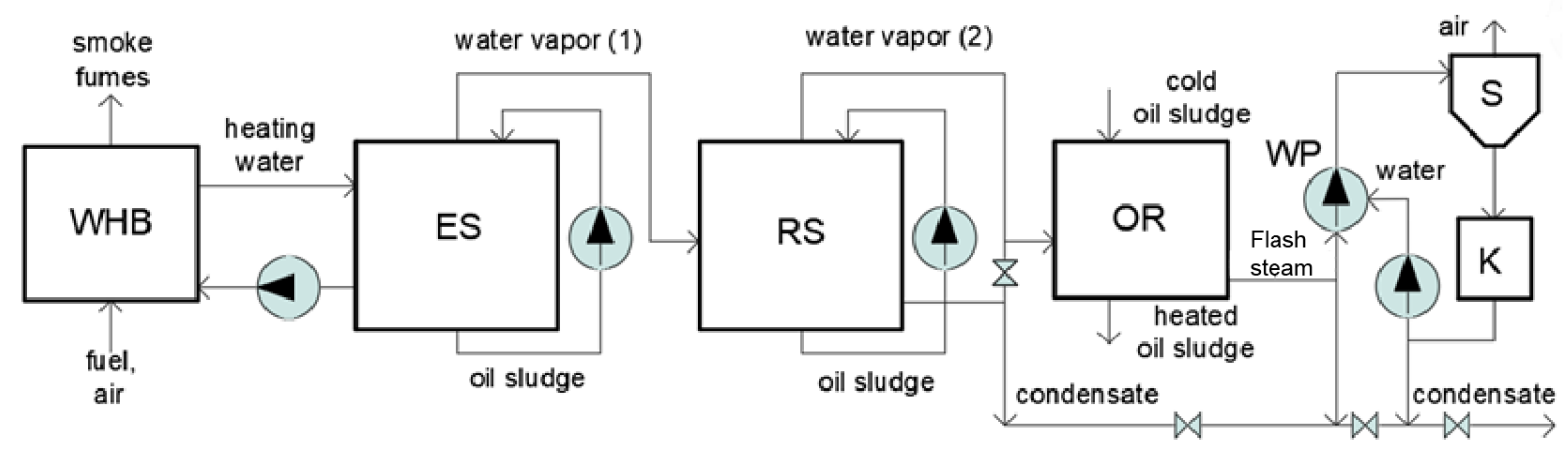

Fig. 1. Thermal scheme of plant for moisture evaporation from oil sludge (BRNSh) with recovery heat exchangers.

Oil sludge is heated to reduce the time of water evaporation at the main stage.

2. After the plant gets into action, the process of evaporation of moisture from oil sludge starts. The primary steam directed to heat the recovery steam stage (RS) is condensed inside the heating pipes. In this case, the condensation heat is spent to moisture evaporation in $\mathrm{RS}$ and to cover the heat losses.

3. The secondary steam leaving RS is sent to heat the recovery heater OR, where the unheated oil sludge is located.

4. The condensate of heating steam, which goes out of recovery stage and heater, is discharged into a container, from which it is drained as necessary.

5. Non-condensed steam and non-condensing gases from the RS recovery stage are sent through the valve through the secondary steam line to the OR.

6. The steam from OR recovery stage is sent to the WP vacuum pump, where it condenses under the influence of cooling water.

7. The resulting mixture of water and gases is sent to separator $\mathrm{C}$ having a discharge into the environment.

8. After removing gases from separator, the remaining heated water from separator $\mathrm{C}$ is fed to the heater $\mathrm{K}$, where it is cooled and then sent to a vacuum pump.

It is advisable to compose the heating surface RS from horizontally arranged pipes with a slight slope for condensate drainage. Inside the pipes, the heating steam condenses, and oil sludge is heated using free convection [6].

Further operation of the heat-recovery evaporation stage $\mathrm{CP}$ is considered in more detail (Fig. 2).

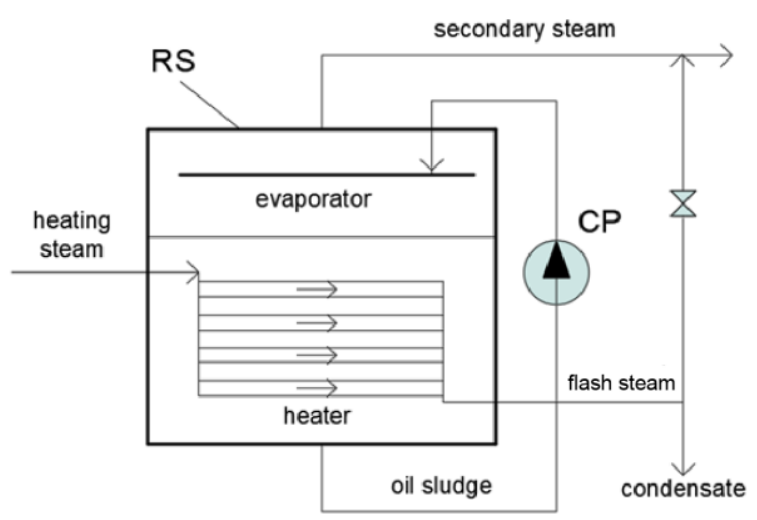

Fig. 2. Schematic diagram of the heat-recovery evaporation stage.

Heated oil sludge is fed into the CP tank. After evaporation process starts in the main evaporation stage, the primary steam leaving it with temperature $t 1$ and pressure $\mathrm{p} 1$ enters the heating pipes of heat-recovery stage, where it condenses at about the same temperature and pressure. Some reduction in steam pressure due to hydraulic losses is not taken into account. After heating of recovery stage begins, the oil sludge is heated to the evaporation temperature $\mathrm{t} 2$, which is determined by pressure $\mathrm{p} 2$ in the tank of recovery stage, after which the process of evaporation of moisture from the oil sludge begins.

Evaporation in the main and heat-recovery stages, connected in series along the steam flow, takes place under vacuum created by the vacuum ring water pump WP. The heated oil sludge is taken from the lower part of tank of evaporation stages by central circulation pumps and fed to evaporator shelves located in the upper part of tank, which serve to increase the mass transfer surface of oil sludge. With partial evaporation of moisture on the shelves of evaporator, the oil sludge is cooled by several degrees, and flows back to the lower part of the stage tanks [7]. 


\section{Operation principle of the plant}

To introduce the necessary parameters into the calculation model, it is necessary to consider the plant operating modes, when evaporation stages operate as evaporators.

Denote the absolute pressure at evaporator stages by $p_{1}$ and $p_{2}$. The corresponding temperatures of steam formed in them are $t_{1}$, and $t_{2}$. The maximum temperature head between the heating steam and oil sludge in the recovery stage is $\Delta t_{\max }=t_{1}-t_{2}[8]$.

The average temperature head is $\Delta t=\zeta \cdot \Delta t_{\max }$. Here the coefficient $\zeta \leq 1$ depends on hydraulic losses during heating steam movement and on flow rate of oil sludge pumped by the circulation pump in the recovery stage and affecting the average oil sludge temperature in the tank [9].

The smaller the hydraulic losses are and the greater the oil sludge flow rate is, the closer is the coefficient $\zeta$ to unity. To minimize hydraulic losses, it is necessary to use a circuit with parallel steam motion inside the heating pipes.

Steam flow rates $G_{1}, G_{2}(\mathrm{~kg} / \mathrm{s})$ are generated in evaporator stages in the set operation mode, and steam flow rate $G_{1}$ is pre-set according to the procedure [3]. Assume heat of condensation (evaporation) of water steam $r_{1}$ and $r_{2}$ at pressures $p_{1}$ and $p_{2}$ are in pressure range of $0.006 \div 0.06 \mathrm{MPa}$ at condensation temperatures of $36.2 \div 85.9{ }^{\circ} \mathrm{C}$. The plant condensation heat varies from 416 to $2293 \mathrm{~kJ} / \mathrm{kg}$.

Suppose $Q_{1=} G_{1} \cdot r_{1}$ is the heat flux (W), which is released during the complete condensation of the primary steam with the flow rate $G_{1}$ inside the pipes of the recovery stage heater; $Q_{2}=G_{2} \cdot r_{2} r_{1}$ is the heat flux (W), which is spent for formation of secondary steam $G_{2}$, and is released during its condensation:

The heat balance of the recovery stage is written in the form:

$$
Q_{2}=\eta \cdot Q_{1}
$$

where $\eta \leq 1$ is the thermal efficiency of recovery stage. Thermal insulation of the outer surface of the stage housing provides a heat balance with efficiency of $\eta \geq$ 0.99 .

If coefficients $\eta=1$ and $r_{=}$const, then for the set mode the condition is fulfilled: $Q_{1=} Q_{2} ; G_{1}=G_{2}$ and the total efficiency of plant is determined by the formula $G \Sigma=2 \cdot G_{1}$. In this case the productivity will increase by about 2 times, the fuel consumption burned in boiler does not change, and the specific fuel consumption (per $1 \mathrm{~kg}$ of evaporated moisture) will decrease by 2 times. to:

The heat flux through the heater RS surface is equal

$$
Q_{1}=\frac{Q_{2}}{\eta}=k \cdot \Delta t \cdot F=k \cdot \zeta \cdot \Delta t,{ }_{\text {max }}
$$

where $k$ is the heat transfer coefficient from heating steam to oil sludge, $\left(\mathrm{W} /\left(\mathrm{m}^{2} \cdot \mathrm{K}\right)\right)$;
$\Delta t$ and $\Delta t_{\max }$ are the average and maximum temperature heads, $\left({ }^{\circ} \mathrm{C}\right)\left(\Delta t_{\max }=t_{1}-t_{2}\right)$;

$\zeta$ is the coefficient which relates $\Delta t$ and $t_{\max }$ $\left(\Delta t=\zeta \cdot t_{\max }\right)$

$F$ is the surface area of heater determined from outer pipe diameter, $\left(\mathrm{m}^{2}\right)$.

If we neglect the hydraulic resistance during the heating steam motion and the change in condensation temperature, then the coefficient $\zeta$ can be calculated by the expression:

$$
\zeta=\left(1+\frac{0.5 \cdot k \cdot F}{W}\right)^{-1},
$$

where $W=c_{0} \cdot G_{0} ; c_{0}$ is the mass heat capacity of oil sludge , $(\mathrm{J} /(\mathrm{kg} \cdot \mathrm{K}))$;

$G_{\mathrm{o}}$ is the mass flow rate of oil sludge pumped by circulation pump $(\mathrm{kg} / \mathrm{s})$.

The latter formula shows that with an infinite increase in $W$, the coefficient $\zeta$ tends to unity, which will require infinite energy expenditures for pumping oil sludge [10].

Figure 3 shows the relationship between coefficient $\zeta$ and $\omega=W /(k \cdot F)$.

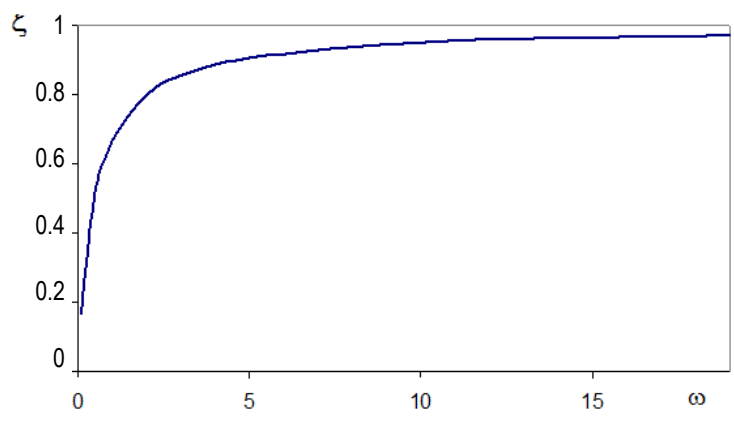

Fig. 3. Relationship between coefficient $\zeta$ and $\omega=W /(k \cdot F)$.

Fig. 3 shows that for $\omega=5(W=5 \cdot k \cdot F)$ the coefficient $\zeta$ $\approx 0.9$. When $\omega$ is increased from 5 to 10 , the coefficient $\zeta$ increases from 0.9 till 0.95 , i.e. for only $5.5 \%$, while electricity consumption $N$ for pumping oil sludge increases by about $2^{3=8}$ times (as $N \sim W^{3}$ ). When $\omega$ is decreased from 5 to 2 the coefficient $\zeta$ decreases from 0.9 to 0.8 , i.e. by $12.5 \%$, while electricity consumption for pumping oil sludge decreases by 15.6 times. Decreasing of $\zeta$ requires the corresponding increase in heater surface, i.e. its price. Optimal values of $\omega$ and $\zeta$ should be determined from technical and economic estimates. One can assume that reasonable value of $\zeta$ is in the range $0.8 \div 0.95$, which corresponds to $\omega=2 \div 10$; and reasonable flow rate of oil sludge is determined using the formula $G_{0}=(2 \div 10) \cdot k \cdot F / c_{\mathrm{o}}[11]$.

The heat transfer coefficient from heating steam to oil sludge $k$ in the recovery stage $\mathrm{RS}$ is determined by expression, as for a flat wall [4]: 


$$
k=\frac{1}{\frac{1}{\alpha_{1}}+\frac{\delta_{c}}{\lambda_{c}}+\frac{1}{\alpha_{2}}},
$$

where $\alpha_{1}$ is the heat exchange coefficient from condensing steam to the inner surface of pipes;

$\alpha_{2}$ is the heat exchange coefficient from outer surface of pipes to oil sludge;

$\lambda_{\text {pw }}$ is thermal conductivity coefficient of pipe wall;

$\delta_{\mathrm{pw}}$ is thickness of pipe walls.

Note that the thermal resistance of heat exchange on the inner surface of pipe $1 / \alpha_{1}$ and pipe wall $\delta_{\mathrm{pw}} / \lambda_{\mathrm{pw}}$ is many times less than the thermal resistance of heat exchange from the outer surface of pipe $1 / \alpha_{2}$. Therefore, in a first approximation, we can take $k \approx \alpha_{2}$. In this case, the average temperatures on the outer and inner surfaces of pipes in the first approximation are equal to $t_{\mathrm{pw} 2} \approx$ $t_{\mathrm{pw} 1}=t_{1}-\delta t_{\mathrm{w}}$, where $t_{1}$ is the temperature of condensation (saturation) of the primary steam; $\delta t_{\mathrm{w}}$ value is a fraction of a degree.

Since coefficient $\alpha_{1}$ is approximately two orders of magnitude higher than coefficient $\alpha_{2}$ and weakly affects the heat transfer coefficient $k$, so the minimal heat exchange coefficient $\alpha_{1}$ can be determined by the Nusselt formula for calculating heat exchange during condensation of stationary steam inside horizontal pipes [12]:

$$
\alpha_{1}=0.65 \cdot\left(\frac{\lambda_{w}^{3} \cdot \rho_{w}^{2} \cdot g \cdot r}{\mu_{w} \cdot \delta t_{w} \cdot d_{i n}}\right)^{0.25},
$$

where thermo-physical parameters of condensate (water) $\lambda_{\mathrm{w}}, \rho_{\mathrm{w}}, \mu_{\mathrm{w}}$ are chosen for the condensation temperature

$t_{1}\left(\lambda_{w}\right)$ is thermal conductivity coefficient;

$\rho_{\mathrm{w}}$ is density;

$\mu_{\mathrm{w}}$ is dynamic coefficient of water viscosity;

$r$ is heat of steam condensation at temperature $t_{\mathrm{s}}$;

$\delta t_{\mathrm{w}=} t_{1}-t_{\mathrm{pw} 1}$ is the difference between temperatures of steam condensation and the inner surface of heating pipe; $d_{\text {in }}$ is the pipe inner diameter.

All values in (4) are presented in SI units.

The heat exchange coefficient to oil sludge $\alpha_{2}$ can be calculated using the well-known formula for calculating heat exchange for free convection of liquid near horizontal pipes [13]:

$$
\alpha_{2}=0.5 \cdot \lambda_{o}\left(\frac{g \cdot \beta_{o} \cdot \delta t_{o}}{v_{o}^{2} \cdot d_{\text {out }}}\right)^{0.25} \cdot\left(\frac{\operatorname{Pr}_{o}}{\operatorname{Pr}_{\mathrm{c} 2}}\right)^{0.25}
$$

where $\lambda_{\mathrm{o}}, \beta_{\mathrm{o}}, v_{\mathrm{o}}$ are coefficients of thermal conductivity, thermal volumetric expansion, kinematic viscosity of oil sludge for its average temperature $t_{\mathrm{o}}$;

$d_{\text {out }}$ is the outer pipe diameter;

$P r_{o}, P_{p w 2}$ are the Prandtl numbers of oil sludge at temperatures $t_{\mathrm{o}}$ and $t_{\mathrm{pw} 2}$; $\delta t_{o}=t_{\mathrm{pw} 2}-t_{o}$ is the difference between temperatures of outer surface of pipes and average temperature of oil sludge.

The average temperature of oil sludge at the recovery stage is determined by the expression

$$
t_{o}=t_{2}+\Delta t_{\max }(1-\zeta)=t_{1}-\zeta \cdot\left(t_{1}-t_{2}\right) .
$$

Temperature $t_{\mathrm{o}}$ is approximately $1 \div 2{ }^{\circ} \mathrm{C}$ more than evaporation temperature $t_{2}$.

The thermal conductivity and viscosity coefficients, as the main thermo-physical properties of oil sludge, affect the coefficient $\alpha_{2}$ and $k$ to a large extent. Thermophysical properties of oil sludge, affecting heat exchange, are weakly dependent on moisture content, if it is less than $30 \%$.

Coefficient $\alpha_{2}$ is significantly affected by temperature difference $\delta t_{\mathrm{o}}$. It is known that $\delta t_{\mathrm{o}}$ is equal to the average temperature head of the considered stage: $\delta t_{\mathrm{o}} \approx \Delta t=t_{1}-t_{\mathrm{o}}$. Expression (5) at $k \approx \alpha_{2} \sim \Delta t^{0.25}$ and density of heat flux from heating flux to $q=k \cdot \Delta t$ shows that $q$ is proportional to $t^{1.25}$.

The values of $k$ and $q$ are determined as follows: assume $\delta t_{\mathrm{o}} \approx \Delta t$, using expression (5) the coefficient $\alpha_{2}$ is calculated in the first approximation, so the heat flux density is $q \approx \alpha_{2} \cdot \Delta t$. Since $q=\alpha_{1} \cdot \delta t_{\mathrm{w}}$, the heat flux on the inner surface of pipe $\delta t_{\mathrm{w}}$ is found from equation (4):

$$
\delta t_{w}=\left(\frac{q}{0.65}\right)^{\frac{4}{3}}\left(\frac{\mu_{w} \cdot d_{i n}}{\lambda_{w}^{3} \cdot \rho_{w}^{2} \cdot g \cdot r}\right)^{\frac{1}{3}} .
$$

From the known $\delta t_{\mathrm{w}}$, the heat exchange coefficient $\alpha_{1}$ on the inner surface of pipes is calculated from expression (4). Further, expression (3) is used to defined $k$ more accurately and to determine heat flux density $q=k \cdot \Delta t$. The value $\delta t_{\mathrm{o}}$ is found from expression: $\delta t_{\mathrm{o}}=\Delta t-$ $q\left(1 / \alpha_{1}+\delta_{\mathrm{pw}} / \lambda_{\mathrm{pw}}\right)$. Using formula (5) one can calculate coefficient $\alpha_{2}$, and determine $q=\alpha_{2} \cdot \delta t_{\mathrm{o}}$

Expressions (6) and (4) are used to find $\alpha_{1}$; expression (3) is used to calculate the heat transfer coefficient $k$.

\section{Computation model}

To perform the calculation, one should take into account the production characteristics of the plant:

- Temperature of the heating steam $t_{1}=75^{\circ} \mathrm{C}$,

- Steam pressure 0.039 MPa.

- Average temperature of oil sludge $t_{\mathrm{o}}=55^{\circ} \mathrm{C}$.

- Average temperature difference between steam and oil sludge $\Delta t=t_{1}-t_{0}=20^{\circ} \mathrm{C}$.

- Heating pipes of heat-recovery stage are horizontal steel pipes Du-40 with outer diameter $d_{\text {out }}=0.048 \mathrm{~m}$, and inner diameter

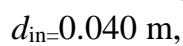

- Thermal conductivity of pipes $\lambda_{\mathrm{pw}}=51.5$ $\mathrm{W} /(\mathrm{m} \cdot \mathrm{K})$. 
Thermo-physical properties of oil sludge are taken according to [5] (transformer oil):

- Heat exchange coefficient $\alpha_{2}$ on the outer surface of heating pipes calculated by (5) for $\delta t_{\mathrm{o}}$ $\approx 20{ }^{\circ} \mathrm{C}, \alpha_{2}=90.9 \mathrm{~W} /\left(\mathrm{m}^{2} \cdot \mathrm{K}\right)$,

- Value $q \approx \alpha_{2} \cdot \Delta t=1818 \mathrm{~W} / \mathrm{m}^{2}$. Value $\delta t_{\mathrm{w}}$, calculated by (6), is $\delta t_{\mathrm{w}} \cong 0.1^{\circ} \mathrm{C}$,

- Heat exchange coefficient $\alpha_{1}$, calculated by (4), is $\alpha_{1=2} 27980 \mathrm{~W} /\left(\mathrm{m}^{2} \cdot \mathrm{K}\right)$,

- Heat transfer coefficient, calculated by (4), is $k=90.1 \mathrm{~W} /\left(\mathrm{m}^{2} \mathrm{~K}\right)$,

- $\quad k \approx \alpha_{2}$, and $\delta t_{\mathrm{o}} \approx \Delta t$

During design calculation inside the evaporator stages of recovery stage for the temperatures of the primary and secondary steam $t_{1}$ and $t_{2}$, coefficient $\zeta$, and flow rate of the primary steam $G_{1}$ from the main stage in evaporation mode, the pressures are taken as $p_{1}$ and $p_{2}$.

Heat flux transmitted during condensation of primary steam is $Q_{1=} G_{1} \cdot r_{1}$. Expressions (3-6) are used to calculate the heat transfer coefficient $k$, and formula (2) is used to determine the necessary area $F$ of heater surface of the recovery stage [14].

The pipes surface area is $F=\pi \cdot d_{\text {out }} l \cdot n$, where $l$ is length of one pipe; $n$ is the amount of pipes.

If to assume $G_{1}=0.031 \mathrm{~kg} / \mathrm{s}$, then for $r_{1}=2320 \mathrm{~kJ} / \mathrm{kg}$ the value $Q_{1}$ is equal to $72.7 \mathrm{~kW}$.

For $\Delta t=20{ }^{\circ} \mathrm{C}$ and $k=90.1 \mathrm{~W} /\left(\mathrm{m}^{2} \cdot \mathrm{K}\right)$ he necessary area of heater surface of the recovery stage is $F=40.3 \mathrm{~m}^{2}$.

As heating pipes we choose horizontal pipes $\mathrm{Du}-40$ of length $l=2.5 \mathrm{~m}$. For the outer pipe diameter $d_{\text {out }}=0.048$ $\mathrm{m}$ the design amount of pipes is $n \approx 112$.

Steam of temperature $t_{2}$, re-entering from the recovery stage RS inflows for heating to OR, where it heats cold oil sludge of mass $M$ of initial temperature $t_{\text {cold }}$ $\approx 25{ }^{\circ} \mathrm{C}$. This heater is a tank facing out, in the bottom of which heating pipes are located. These pipes are immersed in oil sludge, where the secondary steam condenses, and part of it, non-condensed flash steam, is pumped out by a vacuum pump. During OR operation oil sludge is heated approximately to the condensation temperature of the secondary steam $t_{2}$ [15].

The condition for plant operation is $M=M_{1}+M_{2}$, where $M_{1}$ and $M_{2}$ are the oil sludge masses loaded in the main and recovery evaporation stages. Masses $M_{1}$ and $M_{2}$ are selected from the condition that the evaporation process of the main and utilization stages ends simultaneously. The mass ratio of $M_{1}$ and $M_{2}$ can be determined from the heat balance equation:

$$
M_{1} \cdot \varphi \cdot r_{1} \cdot \eta=M_{2} \cdot \varphi \cdot r_{2} \cdot \eta
$$

It is seen that $M_{2} / M_{1}=\eta \cdot r_{1} / r_{2}$. At temperatures $t_{1}=75{ }^{\circ} \mathrm{C}$ and $t_{2}=55{ }^{\circ} \mathrm{C}$ evaporation heat is equal to: $r_{1}=2320 \mathrm{~kJ} / \mathrm{kg} ; r_{2}=2370 \mathrm{~kJ} / \mathrm{kg}$. If assume $\eta=0.98$, then $M_{2} / M_{1} \cong 0.96$.

Part of heat of the secondary steam from RS is spent on heating the oil sludge in recovery stage. For the temperature of cold oil sludge $t_{\text {cold }}$ and the temperature of the heated oil sludge $t_{\mathrm{o}} \approx t_{2}$, the amount of heat spent for its heating will be: $Q_{\mathrm{o}}=c_{\mathrm{o}} \cdot M \cdot\left(t_{\mathrm{o}}-t_{\text {cold }}\right)$. The amount of heat released during condensation of the secondary steam $Q_{\mathrm{s}}=M_{2} \cdot \varphi \cdot r_{2}$, where $\varphi$ is the initial moisture content of oil sludge.

Taking $M_{2} \approx M_{1}, M \approx 2 M_{2} ; \varphi=0.2 ; c_{0}=2.5 \mathrm{~kJ} /(\mathrm{kg} \cdot \mathrm{K}) ;$ $r_{2}=2370 \mathrm{~kJ} / \mathrm{kg} ; t_{\text {cold }}=20{ }^{\circ} \mathrm{C} ; t_{\mathrm{o}=} 55^{\circ} \mathrm{C}$, the ratio of $Q_{\mathrm{o}}$ and $Q_{\text {s }}$ is obtained:

$$
Q_{o} / Q_{s} \cong 2 c_{o} \cdot\left(t_{o}-t_{\text {cold }}\right) /\left(\varphi \cdot r_{2}\right) \approx 0.25
$$

The calculation showed that only a small part of the secondary steam heat can be used to heat the oil sludge. To achieve higher efficiency of this process, it is necessary to calculate the heating surface area of the recovery heater in accordance with the area of the recovery stage [16].

\section{Conclusions}

This work describes a general thermal scheme and a method for thermal calculation of a plant for moisture evaporation from oil products. The authors proposed a thermal calculation for the existing oil sludge separation unit BRNSh-3. As a result of the performed analysis, the technological shortcomings were identified and recommendations were developed to improve thermal efficiency and productivity of the plant. The first recommendation is the need to increase the parameter of thermal power transmitted from the heating water to oil sludge up to the nominal heat output of water boiler. The second recommendation is to use the heat of steam generated during moisture evaporation from oil sludge using a recovery evaporation stage.

\section{References}

[1] Y. Smyatskaya, N. Politaeva, L. Mukhametova, Physico-chemical studies of sorption materials based on biomass waste, E3S Web of Conferences 161, 02003 (2020).

[2] N. Politaeva, V. Prokhorov, E.I. Lezhnev, V.A. Polyanskii, B.G. Matisov, L.R. Mukhametova, I.A. Mukhin, A new approach for recycling of spent activated sludge, IOP Conference Series: Earth and Environmental Science 337, 1, 012077 (2019).

[3] F-R. Ahmadun A. Pendashteh, L.C. Abdullah, D.R.A. Biak, S.S. Madaeni, Z.Z. Abidin, Review of technologies for oil and gas produced water treatment, Journal of Hazardous Materials 170, 530-551 (2009).

[4] A. Al-Futaisi, A. Jamrah, B. Yaghi, R. Taha, Assessment of alternative management techniques of tank bottom petroleum sludge in Oman, Journal of Hazardous Materials 141, 557564 (2007).

[5] A.A. Al-Shamrani, A. James, H. Xiao, Separation of oil from water by dissolved air flotation, Colloids and Surfaces A: Physicochemical and Engineering Aspects 209, 15-26 (2002). 
[6] T. Appleton, R. Colder, S. Kingman, I. Lowndes, A. Read, Microwave technology for energy efficient processing of waste, Applied Energy 81, 85-113 (2005).

[7] A. Surikova, E. Sytsyanko, V.F. Kosmach, Yu.F. Titovec, T.R. Akhmetov, Thermal calculation of the plant for the moisture evaporation from petroleum products, IOP Conf. Series: Earth and Environmental Science 337 (2019).

[8] P.C. Blokker, Spreading and Evaporation of Petroleum Products on Water, Proceedings of the Fourth International Harbour Conference, Antwerp, Belgium, 911-919 (1964).

[9] M. Bobra, A Study of the Evaporation of Petroleum Oils, Manuscript Report Number EE135 (Environment Canada, Ottawa, ON., 1992).

[10] M. Bobra, E.J. Tennyson, Photooxidation of Petroleum, Proceedings of the Twelfth Arctic Marine Oilspill Program Technical Seminar, Environment Canada, Ottawa, Ontario, 129-147 (1989).

[11] P.J. Brandvik, L.-G. Faksness, Weathering Processes in Arctic Oil Spills: Meso-scale Experiments with Different Ice Conditions, Cold Regions Science and Technology, 160-166 (2009).

[12] P.W.M. Brighton, Evaporation from a Plane Liquid Surface into a Turbulent Boundary Layer, Journal of Fluid Mechanics 159, 323-345 (1985).

[13] P.W.M. Brighton, Further Verification of a Theory For Mass and Heat Transfer From Evaporating Pools, Journal of Hazardous Materials 23, 215-234 (1990).

[14] W. Brutsaert, Evaporation into the Atmosphere (Reidel Publishing Company, Dordrecht, Holland, 299, 1982).

[15] J.N. Butler, Transfer of Petroleum Residues from Sea to Air: Evaporative Weathering (Marine Pollutant Transfer, Ed H.L. Windom and R.A. Duce, Lexington Books, Toronto, 201-212, 1976).

[16] P.J. Drivas, Calculation of Evaporative Emissions from Multicomponent Liquid Spills, Environmental Science and Technology 16, 726728 (1982). 